\title{
Gota tofácea
}

\section{Tophaceous gout}

\author{
Luis Guillermo Moreno Madrigal*
}

Hombre de 76 años de edad, con antecedente de hiperuricemia de aproximadamente 40 años de evolución, que se encuentra en tratamiento irregular con alopurinol. Refirió, además, episodios de crisis gotosa aguda en múltiples ocasiones, sin especificar el manejo recibido. Fue hospitalizado por artralgias, aumento de volumen, eritema y calor localizados en ambos codos. A la exploración física, destacaron tofos de gran tamaño en dichas articulaciones (Figuras 1 y 2 2). En sus estudios de

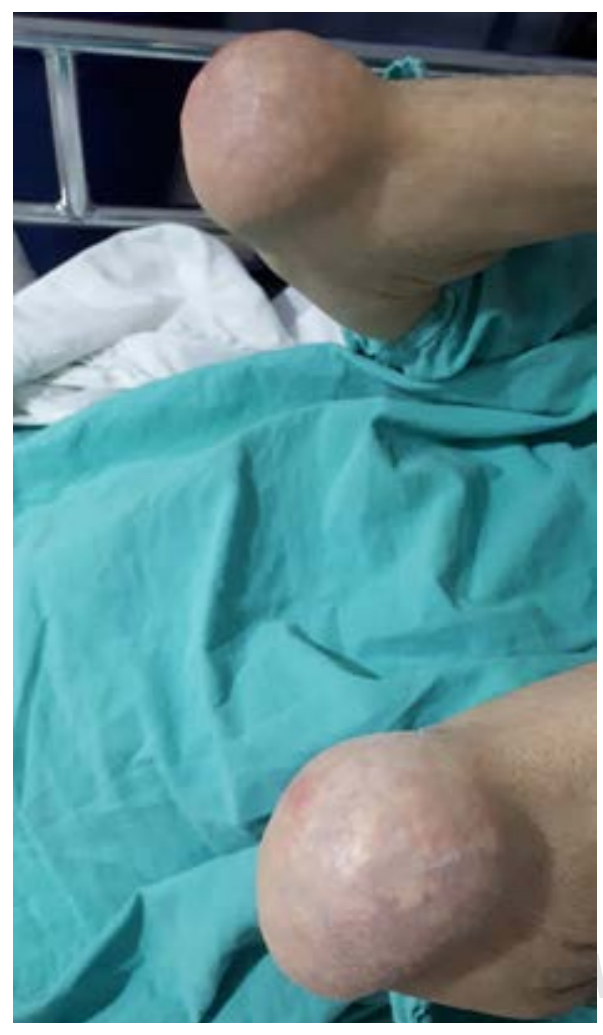

Figura 1. laboratorio, se observaron niveles de ácido úrico de 11.5 $\mathrm{mg} / \mathrm{dL}$, leucocitosis y neutrofilia, descartándose proceso infeccioso alguno. Se indicó colchicina e indometacina, con mejoría considerable en los siguientes días, por lo que fue egresado posteriormente con alopurinol como terapia de mantenimiento.

La gota es un trastorno por depósito crónico de cristales de urato monosódico, que puede ocasionar artritis crónica, tofos, urolitiasis, enfermedad renal, artritis aguda recurrente y bursitis. ${ }^{1}$ La hiperuricemia es su principal factor contribuyente. Su historia natural incluye típicamente cuatro periodos: hiperuricemia asintomática, ataques agudos de gota (artritis gotosa aguda), ataques agudos con intervalos asintomáticos (gota intercrítica) y artritis gotosa crónica. ${ }^{2} \mathrm{El}$ tratamiento para crisis aguda consiste en colchicina, corticosteroides y analgésicos antiinflamatorios no esteroideos; en caso de estar contraindicados o no haber respuesta óptima, puede recurrirse a bloqueadores de interleucina $1 .^{1-3}$

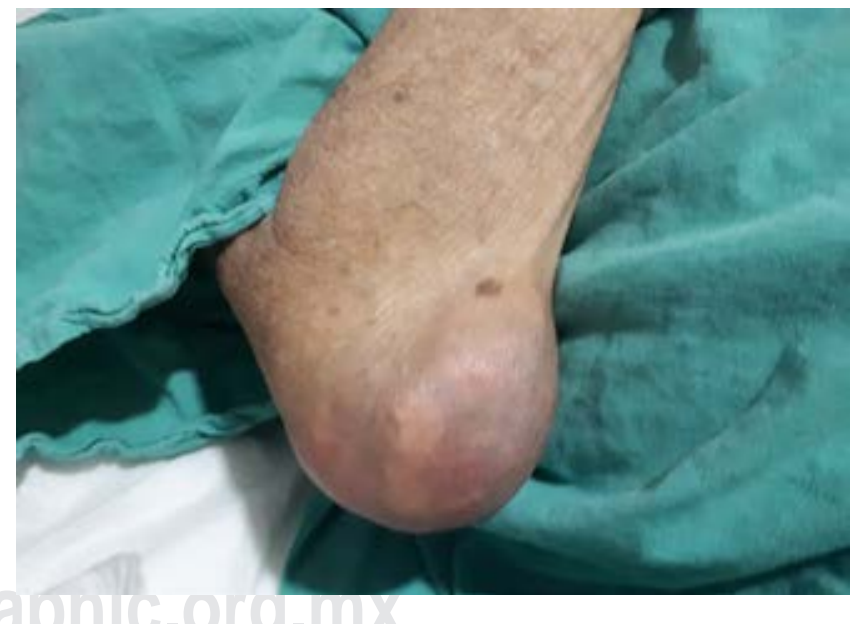

Figura 2.
* Medicina Interna. Hospital General Regional Núm. 1 "Dr. Carlos MacGregor Sánchez Navarro", Instituto Mexicano del Seguro Social. Ciudad de México.

www.medigraphic.com/actamedica
Correspondencia:

Luis Guillermo Moreno Madrigal

Correo electrónico: dr.luismoreno23@gmail.com

Aceptado: 14-06-2019.

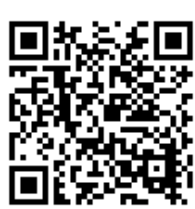




\section{REFERENCIAS}

1. Nuki G, Doherty M, Richette P. Current management of gout: practical messages from 2016 EULAR guidelines. Pol Arch Intern Med. 2017; 127 (4): 267-277.
2. Saigal R, Agrawal A. Pathogenesis and clinical management of gouty arthritis. J Assoc Physicians India. 2015; 63 (12): 56-63.

3. Qaseem A, Harris RP, Forciea MA. Management of acute and recurrent gout: a clinical practice guideline from the American College of Physicians. Ann Intern Med. 2017; 166: 58-68.

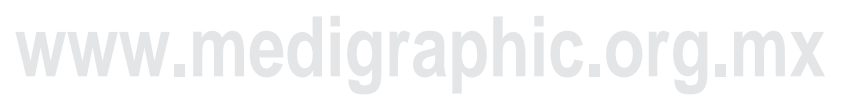

